\title{
Estudos sobre sexualidade, sociabilidade e mercado: olhares antropológicos contemporâneos*
}

\author{
Regina Facchini** \\ Isadora Lins França** \\ Camilo Braz ${ }^{* * * *}$
}

\section{Resumo}

Neste artigo, apresentamos uma revisão crítica com base em 78 trabalhos antropológicos produzidos no Brasil a partir do entrecruzamento das temáticas da sexualidade, da sociabilidade $e$ do mercado. Relacionamos o conjunto de pesquisas aqui trazido com processos sociais e relativos ao campo de estudos antropológicos mais amplos. Identificamos processos de mudança relativos aos objetos empíricos e enquadramentos analíticos mobilizados por tais estudos, produzidos no país desde os anos 1960. Por fim, apontamos como os estudos que partiram de locais de sociabilidade e que, mais recentemente, passaram a tematizar de algum modo o mercado de consumo, constituíram parte muito significativa da produção antropológica brasileira sobre sexualidade, que nas duas últimas décadas cresceu e se diversificou.

Palavras-chave: Antropologia - Brasil, Sexualidade, Gênero, Sociabilidade, Mercado.

\footnotetext{
* Recebido para publicação em 15 de fevereiro de 2014, aceito em 18 de maio de 2014.

** Pesquisadora do Núcleo de Estudos de Gênero Pagu; professora dos programas de pós-graduação em Antropologia Social e em Ciências Sociais, todos na Unicamp. re.facchini@gmail.com

*** Professora do Departamento de Antropologia e pesquisadora do Núcleo de Estudos de Gênero-Pagu, todos na Unicamp. isa.linsf@gmail.com

**** Professor do Departamento de Antropologia e pesquisador do Ser-Tão Núcleo de Estudos e Pesquisas em Gênero e Sexualidade, todos na UFG. camilobraz@gmail.com
} 
Studies on Sexuality, Sociability and Market: Contemporary Anthropological Looks

\begin{abstract}
We hereby bring a critical review based on 65 anthropological works carried out in Brazil and encompassing the themes of sexuality, sociability and market. We relate the investigations presented here to social processes and to processes from the broader field of anthropological studies. We have identified processes of change to empirical objects and analytical frameworks, both of which are mobilized by the aforementioned studies, which have been produced in the country since the 1960s. Finally, we point out how the studies of places of sociability studies which recently have somehow started theming the consumer market - have been a very significant part of the Brazilian anthropological literature on sexuality, which has grown and diversified over the past two decades.
\end{abstract}

Key Words: Anthropology - Brazil, Sexuality, Gender, Sociability, Market. 
Os sentimentos de culpa e pecado que oprimem o homossexual são constantemente repostos por fatores sociais que o levam a se ocultar, a ter medo do ridículo, da prisão, do desemprego, do ostracismo por parte de amigos e familiares. $\mathrm{O}$ gueto é um lugar onde tais pressões são momentaneamente afastadas e, portanto, onde o homossexual tem mais condições de se assumir e de testar uma nova identidade social (MacRae, 1983:56)

No conjunto, pode-se reconhecer uma tendência à comercialização crescente da perambulação homossexual, tanto no seu aspecto de fixação nos bares, boates, saunas, etc, progressivamente diferenciadas enquanto acesso social, quanto no seu sentido mais amplo de "calculização" ou "mercantilização" das transações em geral, que diz respeito à nova convertibilidade dos atributos eróticos postos em atualização pela "modelização" gay (Perlongher, 2008:116-7).

Nos idos da década de 1980, Edward MacRae e Néstor Perlongher, cada um ao seu modo, contribuíram para a constituição de uma perspectiva que buscava as conexões entre os desenvolvimentos recentes no âmbito da homossexualidade e o cenário político-social mais amplo no Brasil, passando pelo que ainda popularmente se conhecia como "gueto" homossexual. As acuradas narrativas etnográficas que dão conta das transformações envolvendo espaços de encontro $e$ territorialidades, somadas à perspectiva dos autores no traçado de conexões e reflexões que extrapolam o contexto imediato de produção de seus trabalhos, ainda hoje têm algo a dizer para os pesquisadores que trabalham com temáticas correlatas.

\footnotetext{
1 Neste artigo, convencionamos grafar categorias êmicas e estrangeirismos em itálico e conceitos ou categorias analíticas entre aspas.
} 
Ambos os trabalhos foram produzidos a partir de um contexto particularmente rico para a antropologia brasileira, que se pluralizava diante das tensões e mudanças sociais que traziam renovada visibilidade a atores como mulheres, homossexuais, negros, moradores de favela e das periferias das grandes cidades, entre outros (Durham, 1986). A saudável tensão produzida entre o contexto político que via emergir as versões modernas de movimentos feministas, homossexuais e negros no Brasil e a reflexão crítica pautada na melhor tradição antropológica deu origem a trabalhos que, dedicando-se à questão das homossexualidades, construíram também uma contribuição original a partir do entrecruzamento de discussões referentes a identidades, sistemas de classificação, política, mercado, territorialidades, configurando desde então um conjunto de questões que iria acompanhar parte importante das pesquisas nesse campo.

Ao longo dos anos, a produção antropológica brasileira sobre sexualidade cresceu e se diversificou. Os estudos que partem de locais de sociabilidade - e que tematizam de algum modo o mercado de consumo - constituem parte muito significativa dessa produção. Neste artigo ${ }^{2}$, esboçamos um mapeamento desses trabalhos e procuramos identificar processos de mudança no que diz respeito aos objetos empíricos e enquadramentos analíticos mobilizados por estudos produzidos desde os anos 1960. Procuramos pensá-los em relação a processos em curso na sociedade e no próprio campo de estudos. De início, contudo, é importante dizer que tais processos de mudança se acentuam ou se tornam mais visíveis a partir da passagem para os anos 2000, quando os esforços empreendidos por pesquisadores e ativistas no

\footnotetext{
2 Agradecemos o apoio do CNPq ao processo 404952/2012-7 de Regina Facchini, à Fapesp pelo apoio ao processo 2011/02760-7 de Isadora Lins França e à FAPEG pelo apoio ao projeto "Nação e Região" do PPGAS/UFG, no qual se inseriu a pesquisa "Memórias, Margens e Mercados - um estudo sobre locais GLS em Goiânia", de Camilo Braz. Esses apoios e as ocasiões de troca com colegas nos grupos de trabalho da ABA, da Anpocs, do Fazendo Gênero e da ABEH foram fundamentais para que este artigo pudesse ser produzido.
} 
campo delimitado por questões relativas a gênero e sexualidade alcançam alguns resultados bastante concretos.

É nesse contexto que observamos a emergência das primeiras políticas públicas que tomam LGBT (lésbicas, gays, bissexuais, travestis e transexuais) como sujeitos de direitos para além da esfera da saúde. Desde meados dos anos 1990, os antigos "guetos" assumiam feições de "mercado segmentado", o coming out dava lugar à multiplicidade das Paradas do Orgulho e o movimento lançava mão de estratégias de incidência política no Executivo e no Legislativo (Facchini, 2009). Em meados dos anos 2000, o movimento LGBT em âmbito internacional conclamava ao reconhecimento de "direitos sexuais" como direitos humanos, o que ecoou no Brasil e se desdobrou em formulações como "um mundo sem racismo, machismo e homofobia", slogan de centenas de Paradas LGBT no ano de 2007. Observamos também um salto quantitativo tanto na criação de grupos de pesquisa sobre gênero e sexualidade no Brasil quanto de grupos de trabalho nos congressos científicos nacionais da Antropologia e das Ciências Sociais (Grossi, 2010; Facchini; Daniliauskas; Pilon, 2013). Perspectivas teóricas se multiplicam, novos olhares e revalorizações de preocupações mais clássicas emergem.

É sob o impacto otimista desses desenvolvimentos e num contexto de multiplicação de sujeitos políticos e de campos de pesquisa na antropologia que se situam cerca de $90 \%$ dos estudos que serviram de base a esta reflexão. $\mathrm{O}$ conjunto analisado inclui 78 trabalhos $^{3}$ produzidos até o ano de $2014^{4}$ e foi composto a

3 Entre os 78 trabalhos analisados, 2/3 (52 trabalhos) se referem à orientação sexual dos sujeitos estudados, sendo que cerca de $1 / 3$ do total (28 trabalhos) tratam especificamente de homossexualidade masculina e 1/4 (17 trabalhos) abordam LGBT ou contextos compartilhados por hetero e homossexuais. Apenas 7 trabalhos tratam mais especificamente de homossexualidade feminina e há diferenças consideráveis nas estratégias metodológicas e nos focos analíticos empregados nesses trabalhos quando comparados aos que focalizam a homossexualidade masculina. São poucos também os trabalhos que tematizam travestis e outras variações de gênero como drag queens, crossdressers ou transformistas (7 trabalhos), sendo que a maior parte dos trabalhos localizáveis nessa temática focaliza prostituição, construção corporal (em contextos médicos 
partir de um recorte metodológico marcado pelo entrecruzamento entre sexualidade/erotismo e etnografia de espaços de sociabilidade. Excluímos tanto os estudos cujo foco principal é a questão da prostituição ${ }^{5}$, quanto aqueles cujo foco são espaços de sociabilidade não relacionados ao lazer, como o espaço doméstico, de práticas religiosas, de iniciativas ativistas ou escolar. Ficaram também fora deste mapeamento, estudos que, apesar de precursores e citados por grande parte dos trabalhos analisados, têm por foco mais específico questões como identidade, sistemas de classificação ou corporalidades, mas não a partir de etnografias em espaços de sociabilidade, tendo como fonte principal dados secundários ou etnografia de redes sociais não situadas territorialmente. Foram considerados trabalhos produzidos no âmbito da antropologia, além de alguns realizados em outras áreas, mas que foram orientados por antropólogos e fizeram uso do método etnográfico.

Entre as principais mudanças observadas estão: 1) na passagem de estudos isolados centrados em contextos de lazer ou encontros sexuais de homens homossexuais para esforços de mapeamento de conjuntos inteiros de estabelecimentos de lazer $e$ sociabilidade e pontos de encontro gays ou GLS; 2) nos esforços

ou não) ou ativismo. Finalmente, cerca de $1 / 6$ dos trabalhos (13 estudos) têm como foco erotismo e/ou práticas sexuais específicas, sendo que seis deles tematizam BDSM (bondage, disciplina, dominação, submissão, sadismo $e$ masoquismo, praticados em contexto erótico); três se voltam para pornografia $e$ quatro outros trabalhos tematizam clubes de swing (troca de casais), sex shops e uso de acessórios eróticos, além de grupos e literatura de autoajuda relacionados a categorias que evocam excessos em relação ao desejo e ao amor.

4 As referências com data posterior a 2012 dizem respeito a estudos que estavam em curso no período do levantamento e foram defendidos ou publicados entre $o$ momento em que produzimos o levantamento $e$ o fechamento deste artigo.

${ }^{5} \mathrm{O}$ tema da prostituição não foi incluído, visto que é abordado por Adriana Piscitelli em outro artigo neste mesmo dossiê. A inclusão do trabalho de Perlongher (2008[1987]) é exceção por oferecer um rico olhar etnográfico para as classificações no interior do que chamou de "gueto", além de seu estudo ter se tornado uma das principais referências para parte importante das pesquisas incluídas neste levantamento. 
renovados na direção de abordar a articulação de marcadores sociais de diferença; 3) na diversificação de objetos empíricos e na recente ênfase em práticas sociais relacionadas à sexualidade que deixam de se pautar necessariamente por dicotomias entre heterohomossexualidade e masculinidade-feminilidade; 4) no esforço em construir um quadro conceitual sobre mercado e consumo, de modo a adensar reflexões relacionadas à sociabilidade em contextos comerciais. O artigo está organizado de modo a explorar cada uma dessas mudanças, considerando os contextos em que se inserem $e$ as articulações entre estudos urbanos, de gênero, de sexualidade e de consumo que permeiam essa produção. Ao final procuramos tecer algumas reflexões críticas inspiradas pela leitura dos trabalhos analisados e por debates acompanhados em congressos na última década.

\section{(Homo)sexualidade masculina, "guetos" e circuitos de lazer e sociabilidade GLS: classificações, identidades e hierarquias sociais}

A maior parte do conjunto de trabalhos voltado para a sociabilidade parte da conhecida trama que conecta espaço urbano a homossexualidade e que se expressa majoritariamente na constituição de espaços comerciais e na conformação de territórios simbolicamente marcados pela presença da homossexualidade nas grandes cidades. Tal articulação é indicada já pelos primeiros estudos voltados para a homossexualidade no âmbito das Ciências Sociais (Lezznoff; Westley, 1998 [1965]; Achilles, 1998[1967]; Warren, 1998[1974]; Levine, 1998[1979]). Esses estudos incorporavam algo do método e do aparato conceitual propostos pelo que se convencionou chamar de Escola de Chicago ${ }^{6}$, com

6 Howard Becker, em período já bastante posterior, mencionou, em entrevista com Gilberto Velho, que não havia uma coerência absoluta em termos de proposta teórica entre os pesquisadores de Chicago de primeira geração. $\mathrm{O}$ termo "Escola de Chicago" deveria ser, antes, compreendido como denominando uma "escola de atividades", no sentido de congregar um conjunto de pesquisadores trabalhando sobre problemas semelhantes e compartilhando métodos e análises (Becker, 1996). 
destaque para a releitura da noção de "gueto", desenvolvida por Louis Wirth (1973[1928]),e para a influência da noção de "região moral", desenvolvida por Robert Park (1973[1915]). Tais noções forneciam uma possibilidade interpretativa para um contexto em que a associação entre determinadas territorialidades, mercado de lazer noturno, prazeres liminares e marginalidade era bastante frequente no imaginário das grandes cidades. Essa aura marginal tem se transformado em certa medida a partir de investimentos públicos e privados que tendem a enquadrar o mercado de lazer noturno como objeto da especulação imobiliária e de processos de "revalorização" urbana.

Embora poucos estudos de Chicago tenham tematizado diretamente a homossexualidade ${ }^{7}$, a abordagem articulando o espaço da cidade a moralidades e o estudo de grupos tidos como "desviantes" promoviam uma ligação direta entre suas contribuições e os estudos que posteriormente se dedicariam à homossexualidade nas Ciências Sociais, como bem aponta Gayle Rubin (2002). No que concerne ao campo dos estudos de gênero $e$ sexualidade no Brasil, a influência de Chicago se dá mais na direção de uma leitura que conecta espaços, territórios $e$ moralidades na cidade do que de um exame mais detido a respeito das noções que permearam os debates nessas primeiras análises sobre a cidade. ${ }^{8}$

Considerações de fundo mais teórico à parte, o mercado na sua porção relacionada à sociabilidade e na sua expressão territorial tem se constituído numa via de acesso para pesquisadores interessados em trabalhar com homossexualidade -

\footnotetext{
7 A etnografia de Nels Anderson (1998 [1923]) é uma das exceções ao destinar uma parte minoritária do estudo a relações sexuais entre homens.

8 Embora "guetos" e "regiões morais" apareçam com certa frequência em muitas dissertações e teses, há, comparativamente, pouca discussão crítica a respeito de tais noções ou mesmo sobre concepções de cidade ou de espaço que as subjazem. Como contra-exemplo, lembramos que Perlongher (2008 [1987]) realiza uma leitura bastante crítica das noções de gueto e região moral, dando forma a uma abordagem singular das dinâmicas observadas em campo, no intuito de enfatizar porosidades e instabilidades próprias do contexto com que trabalhou.
} 
bem como para outros atores sociais, especialmente os relacionados aos serviços de saúde e demais políticas públicas, além de ativistas. ${ }^{9}$

Os trabalhos brasileiros que focalizam mais diretamente a sociabilidade em torno dos estabelecimentos comerciais começam a surgir na década de 1980, com a análise de Perlongher (2008 [1987]) e a reflexão de MacRae (1983) acerca do "gueto paulistano", embora nenhum dos dois repouse suas questões de pesquisa especificamente nesse terreno. Os anteriores a eles, de Barbosa da Silva (2005) e Guimarães (2004) ${ }^{10}$, passam pela questão do "gueto", mas, do ponto de vista metodológico, concentram-se menos num mapeamento ou observação etnográfica e apostam mais no estabelecimento de redes a partir das quais procuram discutir sociabilidades seja no âmbito de estabelecimentos comerciais ou mesmo fora deles.

Além de muito influente em toda a produção que relaciona espacialidades, territórios urbanos, sexualidade, desejo e, eventualmente, mercado, a contribuição de Néstor Perlongher (2008 [1987]) é também referência fundamental para a porção desses trabalhos voltada a espaços de trocas sexuais entre homens. Outro estudo muito influente nesse recorte temático é o de Veriano Terto Jr. (1989), etnografia de uma sala de cinema no

9 Afinal, como já pontuava MacRae (1990), analisando as práticas de ativistas homossexuais da década de 1970, era no "gueto" que a "base" do movimento naquele momento, os "homossexuais" ou os "gays e lésbicas" - poderia ser acessada. Essa escolha, quase "natural" para uma parte dos/as pesquisadores/as, que muitas vezes têm uma experiência pessoal de frequência a estabelecimentos comerciais frequentados por pessoas que gostam de outras do mesmo sexo, eventualmente poderia atuar no reforço de abordagens que supõem certo isomorfismo entre "identidade", "comunidade" e "lugar" (Gupta e Ferguson, 2000) quando não há uma reflexão mais madura de caráter metodológico e teórico na construção das investigações. Entretanto, se por um lado há esse risco, por outro lado os trabalhos têm atestado a imensa diversidade de práticas, desejos, estilos e pertencimentos que constituem a experiência das pessoas que se engajam, com mais ou com menos intensidade, nesse universo.

${ }^{10}$ As datas da produção desses trabalhos são 1958 e 1977, respectivamente. 
Rio de Janeiro que reunia uma multiplicidade de práticas sexuais, notadamente homossexuais.

Ambos se tornaram referências para pesquisas posteriores a respeito de sexo casual ou pegação entre homens, como a pesquisa de Alexandre Vale (2000) no cine Jangada em Fortaleza, a de Élcio Nogueira dos Santos (2012) em saunas de michê na cidade de São Paulo, a de Ricardo Gambôa (2013) em cinemões no centro de São Paulo, ou a de Alexandre Schultz Bier (2004) em cinemas e vídeo locadoras pornôs em Porto Alegre. Outro trabalho nesse mesmo recorte é o de Antonio Cristian Saraiva Paiva (2009) que, ao tematizar o envelhecimento entre homens homossexuais, realiza etnografia em sauna/karaokê em Fortaleza, apontando as saunas como uma espécie de "resistência" dentro de um mercado de lazer que tende a excluir homens mais velhos. ${ }^{11}$ Um último trabalho nesse recorte é o de Camilo Braz (2012a), uma etnografia em clubes de sexo para homens na região central e em bairros de classe média de São Paulo, que parte da discussão antropológica sobre mercado de bens eróticos, consumo $e$ produção de corporalidades e categorias classificatórias para apontar ambivalências da valorização de estereótipos de virilidade nesses lugares. ${ }^{12}$

Para além do recorte em espaços de trocas sexuais, estão os estudos mais voltados para lazer $e$ sociabilidade, sendo que entre esses também são mais frequentes os que tematizam a homossexualidade masculina. ${ }^{13}$ Após os estudos pioneiros já

\footnotetext{
${ }^{11}$ Vale notar que os estudos mais recentes, como os de Paiva (2009) e Santos (2012), enfatizam o fato de que, além de lugar de trocas sexuais, as saunas se constituem como espaços de sociabilidade.

${ }^{12}$ Apesar de a maior parte dos estudos situados em espaços voltados para trocas sexuais ou práticas eróticas ter sido produzida a partir de locais de frequência homossexual masculina, settings de filmagem pornô (Díaz-Benítez, 2010), clubes de swing (von der Weid, 2008; Silveira, 2014), clubes ou festas BDSM/fetichistas (Leite Júnior, 2000; Facchini, 2008 e 2012; Gregori, 2010; Melo, 2010; Freitas, 2012) e mesmo a internet (Parreiras, 2008 e 2012) se constituem em espaços para práticas eróticas ou sexuais.

${ }^{13}$ Não convém exagerar as fronteiras entre os trabalhos que se dedicaram a dinâmicas do mercado de lazer e/ou à sociabilidade e os trabalhos que se
} 
citados, que trabalharam com sociabilidade e classificações entre homens homossexuais entre os anos de 1950 a 1970 a partir de São Paulo e Rio de Janeiro, não foram encontrados trabalhos a partir desse recorte nos anos 1980 e 1990, quando os poucos trabalhos centraram-se em locais de trocas sexuais.

Nos anos 2000, período a partir do qual se observam mudanças importantes no contexto sociopolítico e no campo de estudos, acompanhando a constituição de mercados segmentados em parte das capitais e a expansão geográfica de grupos de pesquisa, mapeamentos de circuitos comerciais de lazer $e$ sociabilidade homossexual passam a se multiplicar em várias cidades e regiões do país. Em nosso mapeamento foram encontrados nove trabalhos com esse perfil, a maior parte produzida como dissertações de mestrado. No entanto, acreditamos que esse seja um dos pontos em que existam mais trabalhos que não puderam ser localizados. Tais estudos demonstram influências explícitas tanto de trabalhos mais clássicos na antropologia que se voltou para a (homo)sexualidade (especialmente, Fry, 1982; Perlongher, 2008[1987]) quanto dos estudos urbanos. Desse modo, trata-se de pesquisas sobre a produção de identidades, classificações, diferenças e hierarquias constitutivas do "circuito homossexual" - geralmente masculino ou predominantemente masculino - ou do "circuito GLS".

Entre esses esforços de mapeamento local, o primeiro é o de Marco Aurélio da Silva (2003) que realiza um mapeamento do "circuito GLS" de Florianópolis a partir do carnaval gay entre 2000 e 2002, identificando o surgimento de espaços de sociabilidade homossexual desde os anos 1970. Em São Paulo, Ronaldo

dedicaram às dinâmicas envolvendo lugares para trocas sexuais ou o mercado do sexo. Embora em termos práticos o diálogo entre os trabalhos se paute por essas fronteiras, é preciso lembrar que as porosidades entre diferentes âmbitos pelos quais as pessoas circulam - $e$ onde buscam constituir relações de amizade, amorosas, sexuais, profissionais, etc - já estão presentes inclusive em alguns dos primeiros estudos envolvendo práticas sexuais na sociologia e antropologia, como os de Humphreys (1970) e Reiss (1961). Apesar disso, uma reflexão mais detida a esse respeito ainda está para se realizar. 
Trindade (2004) realiza um primeiro mapeamento do circuito homossexual masculino desde os trabalhos pioneiros de Barbosa da Silva (2005), MacRae (1983) e Perlongher (2008[1987]). Na região nordeste, há o trabalho de Adriana Prates Sacramento (2005), que analisa o circuito de lazer noturno direcionado a homossexuais em Salvador, concentrando-se especialmente na noção de "gay moderno" e em sua relação com uma "sociedade de consumo". Na região norte, Milton Ribeiro (2012) e Ramon Reis (2012) colaboram para um maior conhecimento do contexto em Belém, sendo que o primeiro realiza um mapeamento do circuito $e$ o segundo autor analisa duas boates frequentadas por homens homossexuais.

Outro trabalho a partir de São Paulo, que acabou por se tornar bastante influente sobre os que se seguiram, é o artigo de Júlio Simões e Isadora Lins França (2005), que, para além do mapeamento do circuito de lazer e sociabilidade homossexual $e$ das reflexões sobre identidades, classificações, diferenças $e$ hierarquias que o constituem, avança no tratamento analítico do mercado, situando a passagem de um "gueto" a um "mercado segmentado de bens e serviços" a partir dos anos 1990. Um mapeamento mais denso e detalhado desse mercado é apresentado por França (2006a) em sua dissertação de mestrado.

Além das influências já citadas, em estudos mais recentes é possível perceber o impacto de desenvolvimentos teóricos a que nos dedicamos no decorrer deste artigo. Esse é o caso do impacto dos estudos feministas e das teorias interseccionais nas pesquisas de Carlos Eduardo Henning (2008), que mapeia o circuito de bares e boates GLS em Florianópolis, e de Regina Facchini (2008), que inclui um mapeamento dos estabelecimentos frequentados por mulheres com conduta homo ou bissexual em São Paulo. É também o caso do impacto de uma perspectiva antropológica sobre consumo e de uma reflexão a respeito de espacialidades $e$ lugares sobre as pesquisas de Isadora Lins França (2012a), que parte do mapeamento anterior para situar relações entre consumo e subjetividade a partir do que a autora considera três lugareschave entre aqueles voltados para homens que gostam de outros 
homens em São Paulo. Camilo Braz (2012b) também se beneficia do debate sobre consumo na antropologia para abordar as narrativas de empresários e frequentadores de lugares de lazer noturno para gays e lésbicas em Goiânia, interpretando antropologicamente as memórias em torno do contexto de surgimento do mercado segmentado GLS ou gay local. ${ }^{14}$

\section{A sexualidade em sua intersecção com outras hierarquias sociais: novas perspectivas}

Perspectivas atentas a como a sexualidade se articula com outras hierarquias sociais, especialmente gênero e classe, estão presentes desde o início da produção antropológica brasileira sobre (homo)sexualidade (Carrara; Simões, 2007), a partir de trabalhos como os de Peter Fry (1982), Néstor Perlongher (2008[1987]), Maria Luiza Heilborn (2004) e Luiz Fernando Dias Duarte (1984). No entanto, a partir dos anos 2000, assistimos a uma revalorização dessa tradição, que acompanha reflexões na literatura feminista em âmbito internacional acerca do descentramento do sujeito político do feminismo.

No plano político, esse processo coincide com a consolidação das políticas públicas focalizadas (inclusive com a criação de estruturas governamentais voltadas para questões de gênero, raciais, de juventude e combate à homofobia, entre outras) e com a crescente multiplicação e especificação de sujeitos políticos no âmbito dos movimentos sociais (Facchini, 2009; Carrara, 2010). Ao mesmo tempo em que, nos últimos anos, se

\footnotetext{
${ }^{14}$ Sobre a cidade de Goiânia, cabe mencionar também recentes dissertações de mestrado que relacionam mercado, consumo e produção de categorias $e$ diferenças a partir de campos etnográficos diversos: a pesquisa de Giórgia de Aquino Neiva (2014) interpreta a questão da fluidez sexual e os limites das categorias classificatórias entre jovens; a de Raphael Moraes Silveira (2014), realizada em um clube de swing da cidade, versa sobre a produção de categorias identitárias e os limites da sexualidade. Os desenvolvimentos teóricos aqui discutidos também influenciaram o estudo de Rodrigo Azócar González (2014), sobre memória e visibilidade gay a partir de etnografia em uma discoteca de Valparaíso, no Chile.
} 
tornou comum encontrar ativistas que atuam simultaneamente em vários movimentos sociais (Facchini; França, 2011), na produção de conhecimento ganham destaque teorias que procuram pensar a constituição mútua de diversos marcadores de diferença ou eixos de diferenciação social (Piscitelli, 2008; Brah, 2006; McClintock, 2010).

Nessa direção, uma série de trabalhos segue explorando a distinção entre camadas médias e populares urbanas (Oliveira, 2006; Lacombe, 2005; Meinerz, 2005; Facchini, 2008), embora com novas preocupações, recortes metodológicos e insights. Leandro de Oliveira (2006), por exemplo, ao articular marcadores de classe, sexualidade e gênero na etnografia de uma boate frequentada por um "público não heterossexual de camadas populares na periferia da cidade do Rio de Janeiro", ressalta a articulação de marcadores sociais no jeito de homem ou de bicha.

María Elvira Díaz-Benítez (2005), inspirada pelas reflexões de Mara Viveros Vigoya, produz um dos primeiros trabalhos brasileiros marcados por uma perspectiva mais intencionalmente interseccional desde o desenho da pesquisa. Sua etnografia em duas boates em Bogotá e no Buraco da Lacraia (região central do Rio de Janeiro) procura pensar a homossexualidade em articulação com raça e classe social em contextos nacionais distintos (Díaz-Benítez, 2005).

Outra contribuição bastante original nessa perspectiva é a de Laura Moutinho (2006) que se debruça sobre o modo como a dinâmica dos afetos e prazeres se cruza com a desigualdade social no circuito GLS carioca, a partir de relatos de jovens negros residentes nas favelas da Maré e de Rio das Pedras. Teoricamente articulado levando em conta as noções de "tensores libidinais" (Perlongher, 2008[1987]) e "campo de possibilidades" (Velho, 1994), o trabalho dialoga com a produção sobre interseccionalidades, tensionando a ideia de que marcadores sociais de diferença possam ser abordados a partir de uma operação de soma de exclusões. As elaborações e o campo iniciado por Moutinho nas favelas cariocas têm impacto direto sobre pelo menos dois outros trabalhos: o de Silvia Aguião (2007), que focaliza sociabilidade e 
sexualidade no contexto da favela Rio das Pedras, matizado a partir de origem regional, cor/raça, gênero; e o de Paulo Victor Leite Lopes (2011) que reflete sobre dinâmicas de sociabilidade, violência e preconceito em contexto de camadas populares, a partir da favela da Maré no Rio de Janeiro, com foco na articulação política de LGBT na favela e na ação de projetos sociais.

Outra entrada teórica para o debate sobre interseccionalidades se dá a partir dos estudos inspirados pelas reflexões de feministas negras, lésbicas e de "terceiro mundo" e de estudos pós-coloniais. Tais contribuições são sistematizadas por Adriana Piscitelli (2008), a partir da diferenciação entre abordagens "sistêmicas" e "construcionistas sociais", ou do foco na "estrutura" ou na "experiência". Entre as autoras classificadas como "construcionistas", nota-se um tensionamento tanto do olhar para a diferença, necessariamente vista como desigualdade, quanto para a articulação de eixos de diferenciação social pensados como soma de exclusões (Brah, 2006; McClintock, 2010). $\mathrm{Na}$ esteira dessa reflexão, temos os trabalhos de Regina Facchini (2008), Isadora Lins França (2012a) e Camilo Braz (2012a), produzidos a partir do contexto paulistano com foco na (homo)sexualidade feminina e masculina, que também se beneficiam do diálogo com os trabalhos desenvolvidos por Moutinho (2006) e Perlongher (2008[1987]).

Apoiados também nos trabalhos anteriormente citados estão os estudos que tratam da articulação entre sexualidade $e$ diferenças geracionais. Nessa vertente, uma das principais referências é o artigo de Júlio Simões (2004) sobre homossexualidade e envelhecimento a partir de observação etnográfica em locais de sociabilidade e lazer para homens mais velhos na região Central de São Paulo. Na esteira desse trabalho estão os de Alexandre Schultz Bier (2004), Elcio Nogueira dos Santos (2012), Carlos Eduardo Henning (2014) e as pesquisas de doutorado em desenvolvimento de Guilherme Passamani (2012) de Gustavo Saggese (2010).

Ainda nessa vertente, mas focalizando jovens, temos as dissertações de mestrado de Alexandre Paulino Vega (2008) e de 
Ane Talita Rocha (2013) sobre o circuito de lazer e sociabilidade de jovens hetero e homossexuais em São Paulo, nas quais se somam reflexões sobre estilo, em interlocução com os insigths de Isadora Lins França (2006b) sobre jovens modernos, e de Regina Facchini $(2008$; 2011) sobre estilos como operadores de diferença. Para além da cidade de São Paulo, no que concerne aos estudos na intersecção entre juventude e sexualidade, estão os trabalhos de Ana Laura Lobato (2011) sobre trajetórias afetivo-sexuais de jovens e sistemas de classificação da sexualidade na favela do Taquaril, Belo Horizonte; Marcelo Perilo (2011) sobre circuitos e percursos de jovens da periferia que frequentam o Parque Vaca Brava, na zona sul de Goiânia, e suas estratégias de negociação do uso do espaço público para sociabilidade; e o de Larissa Pelúcio e Tiago Duque (2011) sobre a frequência de jovens a um conjunto de bares na região central de Campinas, focalizando articulações entre gênero e sexualidade, inclusive entre "meninos femininos" e travestis, o que dá continuidade aos estudos de Duque (2011).

Com preocupações e referências similares está o estudo multicêntrico (Rio de Janeiro, São Paulo, Johanesburgo, Cidade do Cabo, Chicago e São Francisco) coordenado por Laura Moutinho, que tem uma reunião de resultados publicados num dossiê organizado por Laura Moutinho e Sérgio Carrara (2010) nos Cadernos Pagu. Os artigos de Júlio Simões e colaboradores (2010) e Simone Monteiro e colaboradores (2010) trazem os resultados da pesquisa em contextos de lazer e sociabilidade envolvendo jovens nas cidades de São Paulo e Rio de Janeiro, cujas reflexões se centram na intersecção entre raça, sexualidade $e$ outros marcadores sociais de diferença. 
Quando novos objetos entram em cena: variações de gênero ${ }^{15}$, (homo)sexualidades femininas e outras práticas sociais relacionadas à sexualidade

Os estudos que têm como foco variações de gênero (travestis, drag queens ou crossdressers) ou (homo)sexualidades femininas surgem na década de 1990, mas tendem a se adensar apenas em meados da década seguinte. Apesar de numericamente reduzidos, apresentam uma contribuição significativa, distinguindo-se dos anteriormente citados neste artigo: 1) pelas soluções metodológicas que precisam ser encontradas em função de um menor direcionamento de locais de lazer e sociabilidade para essas pessoas e mesmo das estratégias de segregação desse público nos lugares voltados para "gays"; 2) por um deslocamento de certa estabilidade, que perpassa a abordagem da homossexualidade masculina, para uma perspectiva que procura lidar com a maior fluidez das condutas $e$ com a dispersão classificatória gerada a partir da recusa a categorias como "lésbica" fora dos círculos mais próximos do ativismo, bem como das diversas maneiras como variações de gênero são percebidas, vividas e nomeadas; 3) por uma ênfase maior em conjugalidades, família, (in)visibilidade; 4) pela ausência de produção focada para sociabilidade e lugares especificamente voltados para trocas sexuais; 5) pela presença de estudos sobre homossexualidades que focalizam a produção do masculino em corpos de sujeitos assignados ao nascer como do sexo feminino, não segregando variações de gênero e "orientação sexual".

A ênfase em redes ou turmas é uma das soluções metodológicas para a realização de pesquisas tendo em vista a menor presença de mulheres com conduta homossexual em estabelecimentos comerciais voltados para homossexuais. $\mathrm{O}$ primeiro estudo voltado para mulheres e (homo)sexualidade a trabalhar a partir de locais de sociabilidade é o de Luis Octávio

${ }^{15} \mathrm{O}$ termo é tomado de empréstimo de Meinerz (2011). 
Rodrigues Aquino (1992), que investigou duas turmas ${ }^{16}$ de mulheres que viviam em Porto Alegre e Querência (interior do Rio Grande do Sul). Algumas ponderações interessantes trazidas pelo trabalho dizem respeito: 1) aos limites para a transposição de eixos analíticos cunhados com base na pesquisa com homens ao levarse em conta mulheres (especialmente com relação a atividade/passividade); 2) às variações de identidade sexual e de gênero ao longo da trajetória afetivo-sexual (a partir de diferentes relações e da aquisição de experiência sexual); e 3) a maior variação classificatória entre mulheres em comparação ao que se observa entre homens.

Nádia Elisa Meinerz (2005) também desloca o foco no espaço do "gueto" para as relações entre sujeitos, tomando por foco quatro redes, contatadas no âmbito do ativismo ou de bares e boates GLS. Ao observar situações de interação, indica que o espaço de estabelecimento de parcerias homoeróticas femininas extrapola o "gueto", diluindo-se em redes de relações que envolvem amigas $e$ familiares e que têm outros pontos de afinidade para além da homossexualidade (como ter filhos, ter ascendido socialmente via escolarização, ou ter envolvimento com ativismo).

No que diz respeito às limitações metodológicas da busca por sujeitos com condutas homossexuais no "gueto", Regina Facchini (2008) explora a disjunção entre condutas e identidades sexuais e entre estas e as espacialidades. Tal questionamento faz com que a autora produza um mapeamento do "circuito" comercial frequentado por mulheres com conduta homossexual na cidade de São Paulo, embora tensione esse procedimento a partir de outros: 1) exploração de redes de sociabilidade articuladas em torno de outros aspectos que não o sexo da/o parceira/o (uma rede de jovens feministas unidas pelo ativismo cultural riot grrrl e outra de frequentadoras de clubes e festas sadomasoquistas), e 2) a análise da sociabilidade entre mulheres que se relacionam

\footnotetext{
${ }^{16}$ Note-se que turma é uma expressão que também aparece na pesquisa de Thiago Soliva (2012) sobre a Turma OK, num contexto em que nos anos de 1950-60 homossexuais que haviam migrado para a capital carioca se reuniam em turmas que funcionavam como rede de suporte, algo entre a amizade e uma familia.
} 
erótico-afetivamente com mulheres em bairros periféricos e em seus deslocamentos para o centro da cidade.

Outros trabalhos, como os de Silvia Aguião (2007) e Andrea Lacombe (2005), partem de bares e boates como referência, mas exploram elementos específicos a partir de espaços delimitados. Aguião (2007) lança mão de material de uma pesquisa mais ampla para investigar sociabilidade, identidade e corporalidade no circuito comercial de lazer GLS no subúrbio carioca, na articulação entre gênero, orientação sexual, cor/raça e estilos na produção de classificações e hierarquias. Andrea Lacombe (2005) conduz sua pesquisa de mestrado com base na observação de um bar na região central do Rio de Janeiro, frequentado por mulheres de estratos populares. Em sua pesquisa do doutorado, Lacombe (2010) analisa a articulação entre geração e expressão de gênero na conformação de redes de sociabilidade, a partir da etnografia de lugares de encontro de mulheres, investigando, entre outras coisas, a "relevância da apropriação espacial de lugares de lazer nas sociabilidades lésbicas".

As "masculinidades lésbicas" entre grupos populares são tema da pesquisa de doutorado de Nádia Meinerz (2011), realizada a partir de bairros periféricos da região metropolitana de Porto Alegre. A autora enfatiza, entre outras coisas: uma secundarização do papel ocupado pela sexualidade no discurso sobre si; o estabelecimento de relações de afinidade de gênero com homens; os critérios de respeitabilidade e estratégias de afirmação da masculinidade; o lugar ocupado pelas práticas esportivas e laborais para conformação de contornos corporais masculinos entre essas mulheres. Nesse trabalho, assim como nos de Facchini (2008) e Lacombe (2005; 2010), o recorte do campo não separa a homossexualidade de questões relativas à descontinuidade entre sexo assignado no nascimento e expressão de gênero. Isso possibilita que Meinerz (2011) aborde "masculinidades lésbicas" como "formas não discursivas de enunciação da homossexualidade e da atribuição de gênero como prática relacional”. 
A literatura que focaliza variações de gênero entre sujeitos designados como do sexo masculino ao nascer, ao contrário, não só aparece como um corpo de estudos em separado da produção sobre homossexualidade masculina, como é produzida a partir de arranjos metodológicos que raramente incorporam locais de lazer e sociabilidade como cenário para o trabalho etnográfico. Hélio Silva (1992) estuda travestis em seu local de trabalho na prostituição, a Lapa no Rio de Janeiro. Isadora Lins França (2006b) focaliza a ação de uma rede de travestis ativistas para garantir sua frequência a saunas para trocas sexuais entre homens. Tal ação parte da constatação de que a expressão de gênero feminina não era respeitada para lhes garantir acesso a espaços femininos e, portanto, não poderia ser usada para limitar acesso a espaços masculinos como a sauna.

Travestis em espaços de sociabilidade também estão presentes nos estudos de Larissa Pelúcio (2007) e de Tiago Duque (2011). Em sua pesquisa, Pelúcio aborda a vida afetivo-sexual das travestis para além dos limites da prostituição, a partir de locais de sociabilidade $e$ das reuniões frequentadas por travestis chamadas de T-gatas - e seus admiradores - os T-lovers. Tiago Duque (2011) parte de locais comerciais e públicos de sociabilidade GLS na região central de Campinas para falar de mudanças em gerações de travestis jovens, explorando o manejo da prática da "montagem estratégica", que as faz transitarem entre masculinidades $e$ feminilidades com finalidades distintas.

Anna Paula Vencato (2002) constrói seu campo a partir de espaços de sociabilidade GLS de Florianópolis, acompanhando as drag queens que frequentavam tais locais a partir da atividade profissional artística, de modo a analisar a produção do corpo, do gênero e sua encenação nas performances corporais. Seu trabalho se constitui numa etnografia da prática da montação e da fabricação do corpo e da corporalidade montada. Em sua tese de doutorado, Vencato (2013) segue focalizando a montação, mas a partir de outra prática, o crossdressing, analisando a negociação dessa prática na vida cotidiana de crossdressers e o manejo de estigmas associados a vestir-se do sexo oposto ao assignado no 
nascimento. Para tanto, a autora parte das redes na internet (Orkut, listas de discussão e blogs), acessando os encontros promovidos por associadas do Brazilian Crossdresser Club (BCC).

Desde a emergência dos estudos sobre sexualidade na antropologia brasileira, as teorias antropológicas sobre identidade $e$ as teorias construcionistas sociais acerca de sexualidade têm sido apoios teórico-metodológicos para compreender a disjunção entre práticas $e$ identidades sexuais $e$ tomar identidades como categorias relacionais e situacionais a serem analisadas. No entanto, isso ganha outros contornos, dignos de nota, a partir do final dos anos 1990, com a chegada dos queer studies aos centros de pesquisa brasileiros. Se a prostituição, a montação, a pegação, a fechação e a sociabilidade a partir de desejos e práticas homossexuais já vinham sendo abordados na antropologia, o impacto das teorias queer tem levado a esforços renovados na direção de formular objetos de pesquisa a partir de práticas ao invés de identidades. ${ }^{17}$

É nesse contexto que, a partir dos anos 2000, ganham expressão estudos cujo recorte empírico se centra menos nas dicotomias entre homo-heterossexualidade e masculino-feminino do que em dadas práticas sociais relacionadas à sexualidade, como produzir ou consumir pornografia, cursos de pompoarismo, acessórios eróticos, manuais sobre sadomasoquismo ou frequentar redes sociais online, sex shops, clubes para a prática de swing, de BDSM ou grupos de autoajuda para pessoas que se identificam a partir de excessos afetivos ou sexuais (Díaz-Benítez, 2010; Facchini, 2008; Ferreira, 2013; Freitas, 2012; Gregori, 2010; Leite Jr, 2000; 2006;

${ }^{17}$ É verdade que, como assinalam Sérgio Carrara e Júlio Simões neste mesmo dossiê, tal impulso por vezes leva a formulações que acabam por fazer ressurgir como categorias identitárias expressões como "homoerótico", "queer" e "pessoas LGBT", cunhadas no processo de crítica à essencialização de identidades. No entanto, nota-se, por outro lado, uma multiplicação de objetos empíricos que parece acompanhar não apenas a multiplicação de identidades políticas relacionadas a variações de gênero e de sexualidade, como o processo de alargamento dos limites do socialmente aceitável a partir do reconhecimento dos "direitos sexuais" como direitos humanos. 
Melo, 2010; Parreiras, 2008; 2012; Von der Weid, 2008; Zilli, 2007). ${ }^{18}$ Se os estudos sobre (homo)sexualidades femininas e variações de gênero nos incentivam a ultrapassar a abordagem dos bares, boates e circuitos gays ou GLS como universo segregado de outros espaços e relações sociais, o ganho com a ampliação de recortes empíricos para práticas sociais desfocadas das dicotomias heterohomossexual e masculino-feminino parece ter sido o de novamente explicitar as conexões com a ciência, a política e os domínios do mercado, recolocando a sociabilidade mediada por ou em torno de estabelecimentos comerciais de lazer como práticas de consumo.

\section{Sexualidade e erotismo: articulações com consumo, mercado e política}

A preocupação em analisar a produção dos sujeitos ou identidades a partir de variados campos, tais como a ciência, a política e também o mercado tem se caracterizado como elemento distintivo de parte da produção antropológica brasileira recente acerca da sexualidade. Como afirma Gregori,

Hoje não podemos estudar apenas aqueles universos institucionais de produção dos saberes próprios à consolidação da "sociedade burguesa" dos séculos XVIII $e$ XIX, como foi inicialmente realizado por Foucault: clínicas, prisões, processos judiciais. Torna-se estratégico investigar as práticas que envolvem os erotismos, em meio a um universo que parece absolutamente central no mundo contemporâneo: o mercado (Gregori, 2010:77-78).

O desenvolvimento dos trabalhos envolvendo mercado/consumo parece se constituir junto com a demarcação de recortes empíricos: de um lado, há os trabalhos relacionados à homossexualidade, especialmente a masculina, que fundam o

\footnotetext{
${ }^{18}$ Não nos estenderemos sobre essas pesquisas por considerar que já se encontram abordadas no artigo de Maria Filomena Gregori neste dossiê.
} 
campo no Brasil, desde a década de 1960, nos quais o mercado aparece senão como foco central, ao menos como cenário a partir do qual se pode falar de sociabilidades; de outro lado, há a constituição, especialmente nos anos 2010, de um conjunto de trabalhos que se dedicam ao estudo de práticas sexuais na sua intersecção com o mercado sem necessariamente ater-se ao contexto da dicotomia hetero-homo ou masculino-feminino. ${ }^{19}$

Recentemente, tem ganhado espaço nos estudos de gênero e sexualidade uma perspectiva que situa as práticas de consumo no processo de produção de diferenças relacionado à homossexualidade, para além da delimitação de um cenário. Ainda que o recorte empírico seja muitas vezes semelhante, a abordagem tem implicado o aspecto produtivo das práticas de consumo com maior ênfase que os estudos da década de 1980 e 1990 - o que se deve não apenas ao crescimento do mercado relacionado à homossexualidade nas grandes capitais brasileiras $e$ à centralidade que esse contexto vem ganhando no que concerne à constituição de subjetividades, identidades e estilos, mas também à incorporação da literatura antropológica que tem se debruçado sobre o consumo. ${ }^{20}$

A conhecida sentença de Mary Douglas e Baron Isherwood (2004), de que "os bens são neutros, seus usos são sociais; podem ser usados como cercas ou como pontes" serviu como inspiração para o título do trabalho de Isadora Lins França (2006a), que analisou as "cercas e pontes" entre política e mercado, no que diz respeito à produção de categorias identitárias e estilos associados

${ }^{19}$ Cabe notar, porém, que o modo como se constituem os objetos e problemas de pesquisa não tem resultado na constituição de dois campos separados, mas num desenvolvimento muito articulado das temáticas envolvendo sexualidade, sociabilidade e mercado, bem como política e ciência, a partir de diferentes recortes empíricos. Há, no Brasil, assim, alguns trabalhos que partem tanto das heterossexualidades quanto das práticas eróticas que deslocam identidades sexuais como hetero e homossexual. Nesse sentido, são exemplares as pesquisas sobre o swing e o BDSM, bem como sobre pornografia.

${ }^{20} \mathrm{De}$ modo geral, tais trabalhos permitem entrever as dimensões simbólica $e$ social de que se reveste o ato de consumir, bem como a noção de prática de consumo como prática cultural (Douglas e Isherwood, 2004; Sahlins, 2000). 
à homossexualidade, na São Paulo dos anos 2000. Além da atuação política, a autora levou em conta o surgimento do chamado mercado "GLS" (gays, lésbicas e simpatizantes) na cidade para pensar sobre os processos de constituição de identidades homossexuais mediados pelo consumo e pela sociabilidade em lugares de lazer $e$ as relações de aproximação $e$ distanciamento entre movimento social e mercado de consumo. $\mathrm{O}$ estudo de Regina Facchini (2005), que já sugeria a necessidade de se considerar as conexões entre o movimento LGBT e um crescente mercado voltado para gays $e$ lésbicas, $e$ os desenvolvimentos posteriores empreendidos por França, permitem afirmar que o reflorescimento do movimento LGBT e a ampliação e consolidação do mercado relacionado a gays e lésbicas (bares, boates, saunas, revistas, sites, cinemas pornôs, turismo etc.) são processos que ocorreram paralelamente na cidade de São Paulo a partir dos anos 1990 (França, 2006a; Facchini, 2005).

Os trabalhos de França (2006a; 2012b) e Facchini (2005) articulando mercado, sexualidade e política de certo modo dão continuidade a uma reflexão que esteve presente, ainda que de modo lateral, nos primeiros estudos sobre homossexualidade no Brasil: o trabalho de MacRae, publicado em 1983 e republicado em 2005, é uma espécie de resposta ao mais fútil comercialismo atribuído ao "gueto" por atores do movimento (MacRae, 1990), enquanto Perlongher não deixava de perceber as articulações entre categorias identitárias relacionadas à homossexualidade que ganhavam expressão nas territorialidades atravessadas pelos lugares comerciais de encontro e o contexto político do período em que realizou sua pesquisa (Perlongher, 2008 [1987]). Tais conexões seguem sendo realizadas em pesquisas mais recentes, como a de Glauco Ferreira (2012), que analisa as relações entre sujeitos, identidades e direitos desdobrados e negociados no contexto das Paradas, trazendo dados etnográficos sobre o contexto de realização da Parada da Diversidade de Florianópolis. Passamani (2008) realiza, com foco no movimento social, entrevistas com militantes, com não militantes e com empresários na Argentina e no Brasil, tematizando estratégias para lidar com 
homofobia e a importância dos lugares de sociabilidade para a vivência da homossexualidade.

Esses são exemplos de alguns dos trabalhos que dedicam atenção especial às relações entre movimento social e mercado. Embora o Estado e os movimentos sociais sejam as esferas a partir das quais tradicionalmente pensamos o fazer político, é preciso lembrar que as esferas do mercado e do consumo também constituem cenários públicos em que nossa capacidade de agência e ação política é exercida, independentemente de aderirmos ou não a noções como "sociedade do consumo". Nessas esferas, também se negociam direitos, disputam-se significados, enfrentam-se ou reforçam-se desigualdades.

Acreditamos, entretanto, que não apenas problemas de fundo teórico tenham estimulado a produção dessas análises, mas também o trânsito de pessoas, significados e informações entre mercado $e$ movimento, intensificado com as mudanças relacionadas à homossexualidade como lugar social (Carrara, 2005) no Brasil das últimas décadas. Thiago Soliva (2012) aborda com propriedade tais transformações, recuperando a trajetória da Turma OK no Rio de Janeiro, desde os anos 1950, e a atuação da Turma como clube social ou confraria, diferenciando-se ao mesmo tempo do ativismo e do circuito comercial. O autor também enfatiza a centralidade do camp e do transformismo na sociabilidade dos integrantes da Turma e mobiliza marcadores como geração, classe $e$ gênero para entender a dinâmica do campo.

Também relacionadas a mudanças na homossexualidade como lugar social estão a diversificação e a visibilidade adquirida por diferentes cenas urbanas envolvendo a produção de estilos $e$ subjetividades ligados à sexualidade. Nas grandes cidades, esse contexto é atravessado por dinâmicas próprias do mercado de consumo, produzindo segmentação não só no que diz respeito à construção de iniciativas voltadas para gays ou lésbicas no que concerne ao lazer noturno, mas também à segmentação interna dentro dessas próprias iniciativas (França, 2012a).

A construção de subjetividades relacionadas à homossexualidade masculina em contexto de segmentação de 
mercado na cidade de São Paulo foi abordada por França (2012a) por meio de etnografia realizada no que a autora denominou "lugares-chave" no campo: uma grande boate de música eletrônica, uma festa voltada pra ursos (a grosso modo, homens gays, gordos, peludos e masculinos) e um samba GLS. A partir de uma proposta de compreensão do consumo dos lugares e nos lugares onde se realizou a pesquisa, a autora analisa também como se articulam marcadores sociais de diferença - como gênero, sexualidade, classe, idade e cor/raça - atuantes na produção de sujeitos, categorias e estilos relacionados à homossexualidade e como a prática do consumo medeia essa articulação.

Camilo Braz (2012a) dedicou-se, também considerando processos recentes de segmentação de mercado relacionados à homossexualidade, à pesquisa em locais comerciais para encontros sexuais entre homens, notadamente clubes de sexo, na cidade de São Paulo, dialogando com os debates contemporâneos acerca da relação entre "homossexualidades" e "masculinidades" e das relações envolvendo mercados, erotismo e convenções de gênero e sexualidade.

A título de exemplo do potencial comparativo inaugurado pela multiplicação de objetos empíricos, temos o desdobramento da análise iniciada por Facchini (2008), articulando práticas eróticas entre mulheres e BDSM, na direção de aprofundar a reflexão sobre agenciamentos coletivos na "comunidade BDSM". Tais desdobramentos (Facchini; Machado, 2013) têm apontado para a porosidade entre sociabilidade e política e para a possibilidade de pensar na relevância do mercado de bens eróticos para a aproximação e disputa de sentidos por parte de sujeitos interessados em práticas eróticas fetichistas e sadomasoquistas, socialmente menos reconhecidas que a homossexualidade. Nessa direção, contos e romances eróticos emergem como modos mais adequados às suas necessidades do que os regimes de visibilidade impressos pela homossexualidade masculina no âmbito do movimento LGBT. 
Há poucos trabalhos que se voltam para contextos marcados pela não segmentação no contexto do mercado de lazer. Fabiano Gontijo (2009) realizou uma etnografia nas bandas, desfiles, bailes e festas alternativas do Carnaval carioca, buscando compreender os seus significados para "pessoas que mantêm relações sexuais preferencialmente com pessoas do mesmo sexo". Roberto Marques (2012), saindo do eixo sul-sudeste e de capitais, toma as festas de forró eletrônico no Cariri para produzir uma análise sobre gênero e sexualidade numa situação marcada pela presença da "multidão". Bruno Puccinelli (2012) vai ao extremo oposto, analisando como em São Paulo há um contexto de intensa segmentação que passa a se estender para locais de residência $e$ atribuição de identidades sócio-sexuais a ruas, como a Frei Caneca. A internet, a partir dos anos 1990, também integra esses desenvolvimentos, constituindo-se como mais um setor desse mercado, além de tecnologia de produção de novas sociabilidades e de rápida difusão de informações relacionadas à homossexualidade $e$ outras identidades sócio-sexuais (Parreiras, 2008; Zilli, 2007). De todo modo, a produção da diferença e a constituição de subjetividades articuladas ao consumo e ao mercado, em diferentes contextos, seguem sendo um campo fértil de análise, mobilizando um conjunto bastante dinâmico de pesquisas.

\section{Considerações finais}

Para finalizar, gostaríamos de recuperar alguns dos principais argumentos aqui trazidos e fazer um último esforço de distanciamento crítico frente a esse conjunto de estudos, entre os quais se inserem várias de nossas referências, colegas e nossos próprios trabalhos. Para tanto, nos valemos das produções mapeadas, mas também de debates que temos acompanhado em reuniões científicas na última década.

$\mathrm{Na}$ primeira parte nos voltamos aos estudos que, na esteira dos produzidos entre os anos 1960 e 1980, partiram de locais de sociabilidade e de trocas eróticas relacionados à homossexualidade masculina. 
Uma primeira reflexão crítica que poderia ser dirigida a parte desses estudos guarda relação com o impacto do processo de especificação de áreas no interior da antropologia. Nascidos no âmbito dos estudos urbanos, os estudos sobre sexualidade que focalizam contextos de sociabilidade não necessariamente têm guardado o necessário rigor conceitual na utilização de noções como "gueto", "região moral", "sociabilidade", "subcultura" $e$ "circuitos" ou acompanhado os debates mais recentes nos estudos que envolvem o urbano. É preciso ter em conta, especialmente, a confusão semântica que faz com que, em muitos trabalhos, "mercado" ou "circuito" apareçam como termos sinônimos de "comunidade", a circunscrever uma trama muito mais complexa de práticas e identidades. O inverso também é possível: a multiplicação de etnografias para cada estabelecimento comercial, bar ou boate, que se limitam a descrever tais espaços, como uma peça a mais de um quebra-cabeças coletivo.

De maneira semelhante, a noção de sociabilidade não raro aparece sem maiores considerações críticas ${ }^{21}$, utilizada como sinônimo de fruição e do prazer de "estar junto", uma "forma lúdica de sociação", em referência à acepção dada ao termo por Georg Simmel (2006). Essa incorporação até certo ponto irrefletida traz alguma incoerência consigo, pois o conceito de Simmel pressupõe a diluição de posições sociais e suas decorrentes hierarquias e tensões, aspectos com que muitos dos autores se mostram preocupados. ${ }^{22}$

\footnotetext{
${ }^{21}$ É muito frequente, nos estudos que dão mais ênfase à sociabilidade de modo geral, o emprego do termo "circuito" de forma instrumental ou se referindo aos trabalhos de José Guilherme C. Magnani, para descrever ou indicar um conjunto, muitas vezes lido de forma um tanto homogênea, de lugares comerciais de encontro e lazer relacionados à homossexualidade. Uma dificuldade dessa incorporação é a de que os estudos em boa medida descolam a noção de "circuito" da família composta pelo autor ("circuito", "mancha", "pedaço", "pórtico", "trajeto" [Magnani, 2002]) e pouco consideram as problematizações e elaborações em torno de sua proposta.

${ }^{22}$ Como já pontuado por Marylin Strathern (2006), o conceito proposto por Georg Simmel (2006) confere uma carga eminentemente positiva à sociabilidade, não raro relacionada a atividades ligadas ao prazer $e$ a interações afetivas
} 
Uma segunda reflexão crítica relaciona-se ao fato de que participar de um campo de estudos sobre sexualidade (ou gênero e sexualidade) por vezes parece levar a certa confusão entre os problemas de pesquisa e os objetos empíricos. É assim que estudos sobre dado objeto empírico deixam de rever a literatura relacionada a objetos que são similares, mas que são vistos como distantes do recorte do pesquisador, na medida em que esse recorte é entendido estritamente a partir dos sujeitos abordados na pesquisa. A elaboração deste mapeamento não nos deixa dúvidas, por exemplo, de que estudos sobre sociabilidade homossexual masculina e sobre circuitos de lazer e sociabilidade GLS poderiam evitar tomar a sociabilidade de modo isolado de outras relações sociais se levassem em conta os estudos que, abordados na terceira parte deste artigo, produzem alternativas e críticas a partir de variações relacionadas a gênero.

$\mathrm{Na}$ segunda e na terceira partes do artigo, abordamos as contribuições introduzidas principalmente a partir dos anos 2000 por estudos que diversificaram objetos empíricos, ao abordarem a homossexualidade feminina, variações de gênero $e$, mais recentemente, práticas sociais ligadas à sexualidade que não se restringem a dicotomias hetero-homossexualidade ou masculinofeminino, bem como os que retomaram o interesse mais clássico na articulação entre hierarquias sociais a partir de perspectivas interseccionais. Em parte, essas contribuições se devem ao contexto de multiplicação de sujeitos políticos relacionados aos direitos sexuais e à crítica à possibilidade de fragmentação excessiva daí decorrente, mas também por isso incorporam importantes vertentes do debate feminista relacionadas à

marcadas pela leveza. Não podemos descartar a importância dos bares, boates e outros lugares de encontro e sociabilidade principalmente no que está relacionado à homossexualidade e à constituição de categorias de identidade. A noção de sociabilidade parece traduzir a parcela de ludicidade que há nessas iniciativas. Por outro lado, quando empregada de modo pouco refletido, a mesma noção contradiz a produção de diferenças, desigualdades e hierarquias quando não de violência - que envolvem tais contextos de sociabilidade que boa parte das pesquisas descreve empiricamente. 
desnaturalização do sujeito político do feminismo e à abordagem da multiplicidade e constituição mútua das relações sociais de poder que incidem sobre o sujeito "mulheres".

Se esses desenvolvimentos no campo de estudos têm trazido muitos resultados positivos, como assinalamos nas referidas partes deste artigo, há também alguns riscos que convém evitar. $\mathrm{O}$ primeiro deles, mais relacionado à multiplicação de objetos empíricos, diz respeito a cair na fragmentação que nos impeça de identificar a que questões na teoria social $e$ nos estudos de gênero $e$ ou sexualidade eles podem oferecer contribuições. Um modo importante de não perder isso de vista é considerar que o próprio processo de diversificação de objetos empíricos é fruto de um contexto histórico-político específico e que conhecer mais sobre a homossexualidade, a pornografia, o swing, o BDSM ou qualquer outro objeto empírico não constitui por si só justificativa para conduzir um estudo.

No que diz respeito aos estudos que procuram articular marcadores sociais de diferença, tem sido comum encontrar trabalhos que se anunciam como interseccionais, mas pressupõem uma lista prévia de marcadores ou eixos de diferenciação social que não são compatíveis com o que o campo empírico do estudo permite explorar. Outra dificuldade é a restrição prévia de marcadores a serem explorados ou a abordagem em profundidade apenas das articulações com as quais nos sentimos mais confortáveis, ou seja, as que se dão entre gênero $e$ sexualidade. Dois outros problemas que aparecem com frequência são: 1) o enquadramento de fatores relevantes para a análise realizada, mas que não se referem diretamente a relações sociais de poder, como marcadores de diferença - religiosidade, família etc não são, a rigor, marcadores sociais de diferença ou eixos de diferenciação social; 2) a identificação dos marcadores ou eixos relevantes para a análise sem, no entanto, o investimento na compreensão de como se articulam ou se produzem mutuamente para além da pressuposição de efeito cumulativo de diferenças que, desse modo, são automaticamente convertidas em desigualdades. 
A última parte deste artigo se dedicou aos estudos que, a partir de meados dos anos 2000, passam a tomar o mercado $e$ práticas de consumo não mais como cenário em que se estabelece a sociabilidade, mas como foco de análise, em articulação com estudos antropológicos sobre consumo. ${ }^{23}$ Apesar disso, em muitos casos, segue sendo um tanto problemática a incorporação das perspectivas propostas por esses estudos: boa parte das preocupações a respeito do mercado e do consumo relacionados à sexualidade volta-se para a questão da conformação das identidades numa abordagem do consumo que toma o mercado como puro reflexo das diferenças e hierarquias que se verifica no tecido social, numa espécie de denúncia das exclusões e desigualdades. Perde-se, em contrapartida, a compreensão mais refinada das práticas de consumo e de como se produzem tais desigualdades.

Por fim, cabe novamente salientar que nosso mapeamento não tem a pretensão de dar conta de todos os estudos produzidos na antropologia que relacionem, de maneiras diversas, sexualidade, sociabilidade, mercado e consumo no Brasil. Nosso intuito foi esboçar alguns dos caminhos que esses trabalhos vêm traçando, bem como indicar desenvolvimentos e limites que eventualmente têm se apresentado. Por fim, procuramos, ao mesmo tempo, empreender um mapeamento que possibilitasse entrever as relações de retroalimentação entre teoria social (no que concerne a espacialidades e lugares, consumo e mercado, interseccionalidades ou mesmo gênero e sexualidade) e a produção de etnografias no terreno que nos propusemos mapear. Ao adotar essa perspectiva, mais uma vez reforçamos a importância do modo como os estudos de gênero e sexualidade se desenrolam no contexto da antropologia brasileira: antes de circunscrever um campo definido - como de estudos gays $e$ lésbicos ou queer, por exemplo - nos propusemos a abordar os

\footnotetext{
${ }^{23}$ A exemplo do que ocorre no campo da antropologia urbana, há um certo distanciamento na especificação de campos de estudos que ocasiona pouco diálogo com o campo que se tem autodenominado como "antropologia do consumo", com a diferença de que se trata de campo muito menos estabelecido do que os estudos que têm como foco a cidade.
} 
trabalhos que compõem nosso recorte procurando entender as produtivas articulações que estabelecem com debates mais amplos na teoria social e no feminismo e os renovados enquadramentos que propõem.

\section{Referências bibliográficas}

ACHILLES, Nancy. The development of the homosexual bar as in institution. In: NARDI, P. M.; SCHNEIDER, B. E. (orgs.). Social perspectives in lesbian and gay studies: a reader. New York, Routledge, 1998 [1967], pp.175-182.

Aguião, Silvia. "Aqui nem todo mundo igual!": cor, mestiçagem e homossexualidades numa favela do Rio de Janeiro. Dissertação de Mestrado, Ciências da Saúde, UERJ, 2007.

Anderson, Nels. On Hobos and Homelessness. Chicago, University of Chicago Press, 1998 [1923].

AquiNo, Luís Octávio Rodrigues. As derivas do desejo: processos de construção, manutenção e manipulação de identidades lésbicas em um conjunto de mulheres em Porto Alegre. Dissertação de Mestrado, Antropologia Social, UFRGS, 1992.

BARBosa DA SiLVA, J. F. Homossexualismo em São Paulo: estudo de um grupo minoritário. In: GREEN, James N.; TRINDADE, Ronaldo. (orgs.) Homossexualismo em São Paulo e outros escritos. São Paulo: Editora Unesp, 2005 [1958].

BECKER, Howard. A escola de Chicago. Mana (2:2), Rio de Janeiro, 1996, pp.177-188.

BIER, Alexandre Schultz. Sobre cinemas e vídeo-locadoras pornôs, províncias de outros corpos e outros significados. Dissertação de Mestrado, Antropologia, UFRGS, 2004.

BRAH, Avtar. Diferença, diversidade, diferenciação. Cadernos Pagu (26), Campinas, SP, Núcleo de Estudos de Gênero-Pagu/Unicamp, 2006, pp.329-376.

Braz, Camilo. À Meia-Luz... uma etnografia em clubes de sexo masculinos. Goiânia, Editora da UFG, 2012a. 
De Goiânia a "Gayânia": notas sobre o surgimento do mercado "GLS" na capital de Goiás. Paper apresentado na $28^{a}$ Reunião Brasileira de Antropologia. São Paulo, ABA, 2012b.

CARRARA, Sérgio. O Centro Latino-Americano em Sexualidade e Direitos Humanos e o "lugar" da homossexualidade. In: GROSSI, Miriam P. et al. Movimentos sociais, educação e sexualidades. Rio de Janeiro, Garamond, 2005, pp.17-24.

CARRARA, Sérgio. Políticas e direitos sexuais no Brasil contemporâneo. Bagoas (05), Natal, 2010, pp.131-147.

CARRARA, Sérgio; Simões, Júlio. Sexualidade, cultura e política: a trajetória da identidade homossexual masculina na antropologia brasileira. Cadernos Pagu (28), Campinas-SP, Núcleo de Estudos de Gênero-Pagu/Unicamp, 2007, pp.65-99.

DíAz-BEníTEZ, María Elvira. Negros homossexuais: raça e hierarquia no Brasil e na Colômbia. Dissertação de Mestrado, Antropologia Social, UFRJ, 2005.

. Nas Redes do Sexo: os bastidores do pornô brasileiro. Rio de Janeiro, Zahar, 2010.

Douglas, Mary e ISHERWOOD, Baron.O Mundos dos Bens - para uma antropologia do consumo. Rio de Janeiro, Editora UFRJ, 2004.

DUARTE, Luiz Fernando D. Pouca vergonha, muita vergonha: sexo e moralidade entre as classes trabalhadoras urbanas. In: Encontro Nacional de Estudos Populacionais, 4, 1984, Águas de São Pedro. Anais.... [S.l.:s.n.], 1984. vol. 1, p.607-629. Disponível em: $<$ http://www.abep.nepo.unicamp.br/docs/anais/pdf/1984/T84V01A26 .pdf> . Acesso em: 20 jun. 2012.

DUQUE, Tiago. Montagens e Desmontagens - desejo, estigma e vergonha entre travestis adolescentes. São Paulo, Annablume, 2011.

DURHAM, Eunice. A pesquisa antropológica com populações urbanas: problemas e perspectivas. In: CARDOSO, Ruth (org.). A aventura antropológica. Rio de Janeiro, Paz e Terra, 1986.

FACCHINI, Regina. Sopa de letrinhas? Movimento homossexual e produção de identidades coletivas nos anos 90. Rio de Janeiro, Garamond, 2005. 
132 Estudos sobre sexualidade, sociabilidade e mercado

- Entre umas e outras: mulheres, (homo)sexualidade $e$ diferenças na cidade de São Paulo. Tese de Doutorado, Ciências Sociais, Unicamp, 2008.

. "Não faz mal pensar que não se está só": estilo, produção cultural e feminismo entre as minas do rock em São Paulo. Cadernos Pagu (36), Campinas, Núcleo de Estudos de Gênero Pagu/Unicamp, 2011, pp.117-153.

. Comunidades imaginadas: um olhar sobre comunidades políticas a partir de mulheres que se relacionam com mulheres no meio BDSM. Pensata (2), Guarulhos, Unifesp, 2012, pp.6-25.

FACCHINI, Regina; FRANÇA, Isadora Lins. Feminismos jovens Apresentação. Cadernos Pagu (36), Campinas-SP, Núcleo de Estudos de Gênero-Pagu/Unicamp, 2011, pp.9-24.

FaCChINI, Regina; Daniliauskas, Marcelo; Pilon, Ana Cláudia. Políticas sexuais e produção de conhecimento sobre gênero $e$ (homo)sexualidades no Brasil. Revista de Ciências Sociais (44:1), Fortaleza, 2013, pp.161-193.

FACCHINI, Regina; MACHADO, Sarah Rossetti. "Praticamos SM, repudiamos agressão": classificações, redes e organização comunitária em torno do BDSM no contexto brasileiro. Sexualidad, Salud y Sociedad, Rio de Janeiro, 2013, pp.195-228.

FERREIRA, Carolina Branco de Castro. A emergência da adicção sexual, suas apropriações $e$ as relações com a produção de campos profissionais. Sexualidad, Salud y Sociedad(13), Rio de Janeiro, 2013, pp.1-35.

FERREIRA, Glauco. Arco-Íris em disputa: a Parada da Diversidade de Florianópolis entre políticas, sujeitos e cidadanias. Dissertação de Mestrado, Antropologia Social. Florianópolis, UFSC, 2012.

FRANÇA, Isadora Lins. Cercas e pontes. O movimento GLBT e o mercado GLS na cidade de São Paulo. Dissertação de mestrado, Antropologia Social, USP, 2006a.

. "Cada macaco no seu galho?": arranjos de poder, políticas identitárias e segmentação de mercado no movimento homossexual. Revista Brasileira de Ciências Sociais (21:60), São Paulo, 2006b, pp.103-115. 
Consumindo lugares, consumindo nos lugares: homossexualidade, consumo e subjetividades na cidade de São Paulo. Rio de Janeiro, CLAM/EDUERJ, 2012a.

. Sexualidade e política: uma abordagem a partir do mercado e do consumo. Bagoas(07), Natal, 2012b, pp.223-252.

FREITAS, Fátima Regina Almeida de. Bondage, Dominação/Submissão e Sadomasoquismo: uma etnografia sobre práticas eróticas que envolvem prazer e poder em contextos consensuais. Dissertação de Mestrado, Antropologia Social, UFG, 2012.

FRY, Peter. Da hierarquia à igualdade: a construção histórica da homossexualidade no Brasil. In: FRY, Peter. Para Inglês Ver: identidade e política na cultura brasileira. Rio de Janeiro, Zahar, 1982, pp.87-115.

. Estética e política: relações entre "raça", publicidade e produção da beleza no Brasil. In: GOLDEMBERG, Miriam (org.). Nu e Vestido - dez antropólogos revelam a cultura do corpo carioca. Rio de Janeiro, Record, 2002, pp.303-326.

GAMBÔA, Ricardo Fernandes. De prazeres e perigos: abordagem etnográfica dos roteiros eróticos de homens que fazem sexo com homens e desafios à prevenção do HIV na região central da cidade de São Paulo. Dissertação de Mestrado, Saúde Coletiva, Faculdade de Ciências Médicas da Santa Casa de São Paulo, 2013.

Gregori, Maria Filomena. Prazeres Perigosos - erotismo, gênero e limites da sexualidade. Tese - Livre Docência, Unicamp, 2010.

GrossI, Miriam Pillar. Gênero, Sexualidade e Reprodução: A constituição dos estudos sobre gênero, sexualidade e reprodução no Brasil. In: MARTins, C. B.; DuARTE, L. F. D. (orgs.). Horizontes das Ciências Sociais no Brasil: Antropologia. São Paulo, Anpocs, 2010.

GonTIJO, Fabiano. O Rei Momo e o arco-íris: homossexualidade e carnaval no Rio de Janeiro. Rio de Janeiro, Garamond, 2009.

GonZÁleZ, Rodrigo A. Azócar. Pagano: los alternativos del barrio Puerto. Uma mirada etnográfica sobre mercado y visibilidade gay em Valparaíso, Chile. Dissertação de Mestrado, Antropologia Social, UFG, 2014. 
134 Estudos sobre sexualidade, sociabilidade e mercado

Guimarães, Carmem Dora. O homossexual visto por entendidos. Rio de Janeiro, Garamond, 2004 [1977].

GuPTA, Akhil; FERGUSON, James. Mais além da "cultura": espaço, identidade e política da diferença. In: ARANTES, Antonio A. (org). $O$ espaço da diferença. Campinas, Papirus, 2000, pp.30-49.

HEILBORN, Maria Luiza. Dois é par: gênero e identidade sexual em contexto igualitário. Rio de Janeiro, Editora Garamond, 2004.

HENNING, Carlos Eduardo. As diferenças na diferença: hierarquia e interseções de geração, gênero, classe, raça e corporalidade em bares $e$ boates GLS de Florianópolis, SC. Dissertação de Mestrado, Antropologia Social, UFSC, 2008.

. Paizões, tiozões, tias e cacuras: envelhecimento, meia-idade, velhice e homoerotismo masculino na cidade de São Paulo. Tese de Doutorado, Antropologia Social, Unicamp, 2014.

HUMPHREYS, Laud. Tearoom trade: impersonal sex on public places. Chicago, Aldine, 1970.

LACOMBE, Andrea. "Pra homen já tô eu": masculinidades e sociabilidades lésbicas em um bar do centro do Rio de Janeiro. Dissertação de Mestrado, Antropologia Social. UFRJ, 2005.

. Ler [se] nas Entrelinhas. Sociabilidades e subjetividades entendidas, lésbicas e afins. Tese de Doutorado, Antropologia Social, UFRJ, 2010.

LEITE JR, Jorge. A Cultura SM. Trabalho de Conclusão de Curso, Ciências Sociais, PUC-SP, 2000.

- Das Maravilhas e Prodígios Sexuais - A pornografia "bizarra" como entretenimento. São Paulo, Annablume, 2006.

LeVine, Martin P. Gay ghetto. In: NARDI, P. M.; SchneIder, B. E. (Ed.). Social perspectives in lesbian and gay studies: a reader. New York, Routledge, 1998 (1979). pp.194-206.

LEZNOFF, M.; WeSTLEY, W.A.The homosexual community. In: NARDI, P. M.; SCHNEIDER, B. E. (Ed.). Social perspectives in lesbian and gay studies: a reader. New York, Routledge, 1998 [1965]. pp.5-11. 
LOBATO, Ana Laura. Trajetórias Afetivas e Sexuais entre Jovens de Periferia, Belo Horizonte. Dissertação de Mestrado, Antropologia Social, Unicamp, 2011.

LOPES, Paulo Victor Leite. Sexualidade e Construção de si em uma Favela Carioca: pertencimentos, identidades, movimentos. Dissertação de Mestrado, Antropologia Social, UFRJ, 2011.

MACRAE, Edward. A Construção da Igualdade - Identidade sexual e política no Brasil da abertura. Campinas, Editora da Unicamp, 1990 [1986].

. MACRAE, Edward. Em defesa do gueto. Novos Estudos CEBRAP (2:1), São Paulo, 1983, pp.53-60.

MAGNANI, José Guilherme C. De perto e de dentro: notas para uma etnografia urbana. Revista Brasileira de Ciências Sociais (49), São Paulo, 2002, pp.11-29.

MARQUES, Roberto. O Cariri do Forró Eletrônico: festa, gênero e criação no Nordeste contemporâneo. Tese de Doutorado, Ciências Humanas - Antropologia, UFRJ, 2012.

MCClintock, Anne. Couro imperial. Raça, gênero e sexualidade no embate colonial. Campinas, Ed. da Unicamp, 2010.

MEINERZ, Nádia Elisa. Estudo Etnográfico sobre a Constituição da Parceria Homoerótica Feminina em Segmentos Médios na Cidade de Porto Alegre - RS. Dissertação de Mestrado, Antropologia Social, UFRGS, 2005.

. Mulheres e Masculinidade: etnografia sobre afinidades de gênero no contexto da parceria homoerótica feminina em grupos populares. Tese de Doutorado, Antropologia Social, UFRGS, 2011.

MELO, Marília Loschi de. A dor no corpo: identidade, gênero e sociabilidade em festas BDSM no Rio de Janeiro. Dissertação de Mestrado, Ciências Sociais, UERJ, 2010.

MONTEIRO, Simone et al. Identidades, trânsitos e diversidade sexual em contextos de sociabilidade juvenil no Rio de Janeiro (Brasil). Cadernos Pagu(35), Campinas-SP, Núcleo de Estudos de GêneroPagu/Unicamp, 2010, pp.79-109. 
136 Estudos sobre sexualidade, sociabilidade e mercado

MoUTINHO, Laura. Negociando com a adversidade: reflexões sobre "raça", (homos)sexualidade e desigualdade social no Rio de Janeiro. Revista Estudos Feministas (14), UFSC, 2006, pp.103-116.

MoutinHO, Laura; CARRARA, Sérgio. Apresentação. Cadernos Pagu(35), Campinas-SP, Núcleo de Estudos de Gênero-Pagu/Unicamp, 2010, pp.1-26.

NEIVA, Giórgia de Aquino. Nas redes dos alternativos: mercado, sexualidade e produção de diferenças na cidade de Goiânia. Dissertação de Mestrado, Antropologia Social, UFG, 2014.

OLIVEIRA, Leandro de. Gestos que pesam: performance de gênero $e$ práticas homossexuais em contexto de camadas populares. Dissertação de Mestrado, Saúde Coletiva, UERJ, 2006.

PAIVA, Antônio Cristian S. Pulsão invocante e constituição de sociabilidades clementes: notas etnográficas sobre karaokê numa sauna em Fortaleza. Trabalho apresentado no Encontro Anual da Anpocs. Caxambu, Anpocs, 2009.

PARK, Robert Ezra. A cidade: Sugestões para a investigação do comportamento humano no meio urbano. In: VELHO, Gilberto. $O$ Fenômeno Urbano. Rio de Janeiro, Zahar, 1973, pp. 29-72.

PARREIRAS, Carolina. Sexualidades no pontocom: espaços e homossexualidades a partir de uma comunidade on-line. Dissertação de Mestrado, Antropologia Social, Unicamp, 2008.

. Entre o Alternativo e o Mainstream: uma etnografia das representações pornográficas on-line e off-line. Relatório de Qualificação de Doutorado, Ciências Sociais, Unicamp, 2012.

PASSAMANI, Guilherme. Arco-íris (Des)coberto: homossexualidades masculinas, movimentos sociais e identidades regionais - os casos de Porto Alegre e Buenos Aires. Dissertação de Mestrado, Integração Latino-americana, UFSM, 2008.

. Homossexualidades masculinas, envelhecimento e memória no interior de Mato Grosso do Sul. Projeto de Pesquisa de Doutorado, Ciências Sociais, Unicamp, Campinas, 2012.

PElÚCIO, Larissa. Abjeção e Desejo - uma etnografia travesti sobre o modelo preventivo de aids. São Paulo, Editora Annablume, 2009. 
PElÚCIO, Larissa; DUQUE, Tiago. "...depois, querida, ganharemos o mundo": reflexões sobre gênero, sexualidade e políticas públicas para travestis adolescentes, meninos femininos e outras variações. Revista de Ciências Sociais (44:1), Fortaleza, 2013, pp.10-43.

PERILO, Marcelo. Eles Botam o Bloco na Rua! Uma etnografia sobre sociabilidades juvenis. Dissertação de Mestrado, Antropologia Social, UFG, 2012.

PERLONGHeR, Nestor. O negócio do michê: prostituição viril em São Paulo. São Paulo, Perseu Abramo, 2008[1987].

PISCITELli, Adriana G. Intersecionalidades, categorias de articulação e experiências de migrantes brasileiras. Sociedade e Cultura (11:2), Goiânia, 2008, pp.263-274.

PuCCINELli, Bruno. Se Essa Rua Fosse Minha: sexualidade e apropriação do espaço na rua gay de São Paulo. Dissertação de Mestrado, Ciências Sociais, São Paulo, Unifesp, 2013.

REIS, Ramon. Encontros e Desencontros: uma etnografia das relações entre homens homossexuais em espaços de sociabilidade homossexual de Belém, Pará. Dissertação de Mestrado, Ciências Sociais - concentração em Antropologia, UFPA, 2012.

REISS JR., Albert J. The social integration of queer sandpeers. Social Problems (9), 1961), pp.102-120.

RiBeIRO, Milton. Na Rua, na Praça, na Boate: uma etnografia da sociabilidade LGBT no circuito GLS de Belém-PA. Dissertação de Mestrado, Ciências Sociais - concentração em Antropologia, UFPA, 2012.

RochA, Ane Talita da Silva. Construindo desejos e diferenças: uma etnografia da cena indie rock paulistana. Dissertação de mestrado, Antropologia Social, São Paulo, USP, 2013.

RUBIN, Gayle. Studying sexual subcultures: excavating the ethnography of gay communities in Urban North America. In: LEWIN, Ellen; LEAP, William L. (orgs.) Out in theory: the emergence of lesbian and gay anthropology. Chicago, University of Illinois Press, 2002, pp.17-68.

SACRAMENTO, Adriana Prates. Homossexualidade, "modernidade", consumo e hierarquia: um estudo sobre a relação entre identidade $e$ 
consumo na contemporaneidade. Dissertação de Mestrado, Ciências Sociais, UFBA, 2005.

SAgGESE, Gustavo. Homossexualidade masculina, mudança social e geração: observações de um campo em curso. In: PASSAMANI, Guilherme Rodrigues. (Org.). (Contra)pontos: Ensaios de Gênero, Sexualidade e Diversidade sexual - Cursos da Vida e Gerações. Campo Grande, Editora UFMS, 2013, pp.107-119.

SAHLINS, Marshall. Cultura e Razão Prática. São Paulo, Zahar, 2003.

SANTOS, Élcio Nogueira dos. Amores, Vapores e Dinheiro masculinidades, homossexualidades nas saunas de michês em São Paulo. Tese de Doutorado, Ciências Sociais, PUC-SP, 2012.

SiLVA, Hélio R. Santos. Lapa de Travestis. Dissertação de Mestrado, Antropologia Social, UFRJ, 1992.

SILVA, Marco Aurélio. Se manque: uma etnografia do carnaval no pedaço GLS da Ilha de Santa Catarina. Dissertação de Mestrado, Antropologia Social, UFSC, 2003.

SiLVEIRA, Raphael Moraes. Nem tudo é possível, e muita coisa é obrigatória: um estudo da prática do swing em Goiânia. Dissertação de Mestrado, Antropologia Social, UFG, 2014.

SIMMEL, Georg. A sociabilidade (exemplo de sociologia pura ou formal). In: SIMMEL, Georg. Questões fundamentais da sociologia. Rio de Janeiro: Zahar, 2006, pp.165-181.

SIMÕES, Júlio Assis. Homossexualidade Masculina e Curso da Vida: pensando idades e identidades sexuais. In: CARRARA, Sérgio; GREGORI, Maria Filomena; PISCITELLI, Adriana. (orgs.). Sexualidade e Saberes: Convenções e Fronteiras. Rio de Janeiro, Garamond, 2004, pp.415-447.

SIMÕES, Júlio; FRANÇA, Isadora Lins. Do gueto ao mercado. In: GREEN, James; TRINDADE, Ronaldo (Orgs.). Homossexualismo em São Paulo e outros escritos. São Paulo, Editora da Unesp, 2005, pp.309-333.

SIMÕES, Júlio Assis; FRANÇA, Isadora Lins; MACEDO, Marcio. Jeitos de corpo: cor/raça, gênero, sexualidade e sociabilidade juvenil no centro de São Paulo. Cadernos Pagu(35), Campinas, SP, Núcleo de Estudos de Gênero-Pagu/Unicamp, 2010, pp.37-78. 
SolivA, Thiago Barcelos. A Confraria Gay: um estudo de sociabilidade, homossexualidade e amizades na Turma OK. Dissertação de Mestrado, Sociologia e Antropologia, UFRJ, 2012.

STRATHERN, Marilyn. O Gênero da Dádiva:problemas com as mulheres e problemas com a sociedade na Melanésia. Campinas, Editora da Unicamp, 2006.

TERTO JUNIOR, Veriano de Souza. No Escurinho do Cinema...: Socialidade orgiástica nas tardes cariocas. Dissertação de Mestrado, Psicologia, PUC-RJ, 1989.

TRINDADE, Ronaldo. De Dores e de Amores: Transformações da homossexualidade paulistana na virada do século $\mathrm{XX}$. Tese de Doutorado, Antropologia Social, USP, 2004.

VALE, Alexandre Fleming Câmara. No escurinho do cinema: cenas de um público implícito. São Paulo, Annablume, 2000.

VEGA, Alexandre Paulino. Estilo e marcadores sociais da diferença em contexto urbano: uma análise da desconstrução de diferenças entre jovens em São Paulo. 2008. Dissertação de Mestrado, Antropologia Social, USP, 2008.

VelHO, Gilberto. Projeto e metamorfose: antropologia das sociedades complexas. Rio de Janeiro, Jorge Zahar Editores, 1994.

VencATO, Anna Paula. Fervendo com as Drags: corporalidades $e$ performances de drag queens em territórios gays da Ilha de Santa Catarina. Dissertação de Mestrado, Antropologia Social, UFSC, 2002. . Sapos e Princesas: prazer e segredo entre praticantes de crossdressing no Brasil. São Paulo: Annablume, 2013.

VON DER WEID, Olivia. Adultério Consentido: gênero, conjugalidade e sexualidade na pratica do swing. Dissertação de Mestrado, Sociologia e Antropologia, UFRJ, 2008.

WARren, Carol. Space and time. In: NARDI, P. M.; Schneider, B. E. (Ed.). Social perspectives in lesbian and gay studies: a reader. New York, Routledge, 1998 [1974], pp.183-193.

WIRTH, Louis. The ghetto. Chicago, University of Chicago, 1928. 
140 Estudos sobre sexualidade, sociabilidade e mercado

ZILLI, Bruno D. A perversão domesticada: estudo do discurso de legitimação do BDSM na internet e seu diálogo com a psiquiatria. Dissertação de Mestrado, Saúde Coletiva, UERJ, 2007. 